\title{
Multimodal use of indocyanine green endoscopy in neurosurgery: a single-center experience and review of the literature
}

\author{
Giuseppe Catapano $^{1} \cdot$ Francesco Sgulò $^{2}$ - Lili Laleva ${ }^{3}$ - Laura Columbano ${ }^{1}$. \\ Iacopo Dallan ${ }^{4} \cdot$ Matteo de Notaris $^{1}$ (D)
}

Received: 7 March 2017 / Accepted: 13 April 2017 / Published online: 6 May 2017

(C) The Author(s) 2017. This article is an open access publication

\begin{abstract}
During the last 10 years, microscope-integrated indocyanine green fluorescence ( $\mathrm{m}-\mathrm{ICG}$ ) has been widely used for assessing real-time blood flow during aneurysm surgery. More recently, an endoscope-integrated indocyanine green fluorescence (e-ICG) has been adopted as a versatile tool during different endoscopic neurosurgical procedures. The purpose of the present report is to evaluate multimodal applications of e-ICG during different endonasal, intraventricular, aneurysm and brain tumor surgeries and provide technical nuances. In addition, we reviewed the literature and identified and compare several overlapping case series of patients treated via an endoscopic integrated indocyanine green fluorescence technique. A total of 40 patients were retrospectively evaluated. Patients were divided into four main groups: (1) endoscopic endonasal approaches $(n=14)$; (2) ventricular endoscopic approach including patients undergoing third ventriculostomy ( $n=8)$ and tumor biopsy $(n=1)$; (3) aneurysms surgery $(n=9)$; and (4) brain parenchymal tumors $(n=8)$. All patients were successfully treated using the eICG dynamic endoscopic visualization, and there were no
\end{abstract}

Electronic supplementary material The online version of this article (doi:10.1007/s10143-017-0858-4) contains supplementary material, which is available to authorized users.

Matteo de Notaris

matteodenotaris@gmail.com

1 Department of Neuroscience, Neurosurgery Operative Unit, "G. Rummo" Hospital, Via Pacevecchia no. 53, 82100 Benevento, Italy

2 Division of Neurosurgery, Department of Neurological Sciences, Università degli Studi di Napoli Federico II, Naples, Italy

3 Department of Neurosurgery, Tokuda Hospital Sofia, Sofia, Bulgaria

4 First Otorhinolaryngologic Unit, Azienda Ospedaliero-Universitaria Pisana, Pisa, Italy perioperative complications. Such unique features open up a promising field of applications beyond the use of $\mathrm{m}-\mathrm{ICG}$ in different surgical field due to the longer duration of e-ICG fluorescence up to $35 \pm 7 \mathrm{~min}$. E-ICG represents a new and effective technique for longer real-time visualization of vascular structures preserving normal tissues and functions during different transcranial and endonasal approaches. As the technology and e-ICG resolution improves, the technique has the potential to become a critical tool for different applications in neurosurgery.

Keywords Indocyanine green videoangiography · Endoscopy · Transsphenoidal · Third ventricle · Aneurysm • Brain tumors

\section{Introduction}

Indocyanine green (ICG) angiography has become a wellestablished technology in several surgical fields, including ophthalmology, general, plastic, vascular, cardiac and head and neck surgery [1-8]. The principle of fluorescence imaging used during ICG videoangiography is simple: illuminate the tissue of interest with light at the excitation wavelength (about 750 to $800 \mathrm{~nm}$ ) while observing it at longer emission wavelengths (over $800 \mathrm{~nm}$ ). The confinement of indocyanine to the vascular compartment through binding with plasma proteins, the low toxicity and the rapid excretion, almost exclusively into the bile, represents the main advantages of this visualization tool.

Concerning neurosurgery, microscope-integrated indocyanine green $(\mathrm{m}-\mathrm{ICG})$ angiography was firstly adopted in vascular surgery by Raabe $[9,10]$ in 2003 . The technique enabled the real-time evaluation of exposed vessel patency during surgery, configuring as an adequate alternative to intraoperative 
arteriography (IOA) and a clinical tool to reduce rates of incomplete clipping or occlusion of surrounding vessel aneurysms in vascular surgery. During the years that followed, increased versatility and minimized invasiveness relative to IOA has facilitated the use and diffusion of m-ICG beyond the field of vascular surgery, i.e., during brain and spinal procedures as well as pituitary surgery [11-15]. More recently, with the development of an endoscope with integrated green indocyanine (e-ICG) filter first adopted in vascular surgery to verify the patency of vessels hidden from microscopic view, the increased effectiveness of this novel tool in different fields of neurosurgery has also been reported. Currently, the four main application fields of e-ICG are neurovascular [16-18], endoscopic endonasal approaches [19-21], ventricular surgery $[22,23]$ and neurooncological $[22,24]$. As a matter of fact, employing the e-ICG dynamic technique in different surgical scenarios, such as in fluorescence-guided resection of brain and pituitary tumors as well as neuroendoscopic approaches, the management of a wide spectrum of pathological conditions shows promise for future development.

We therefore designed a multimodal study to evaluate the safety and feasibility of intravenous application of indocyanine in combination with the e-ICG visualization in patients undergoing various endonasal, ventricular, aneurysm and brain tumor surgeries and perform a comprehensive review of the literature.

\section{Material and methods}

The present retrospective study examined a total of 40 consecutive patients treated in our Institution from January 2015 to June 2016. All interventions were performed using the eICG as the sole visualizing tool with the exception of aneurysm and brain tumor surgery in which the endoscope was used in combination with the microscope (endoscope-assisted technique). In all cases, neuronavigation (Medtronic S7 StealthStation, Louisville, CO, USA) was used to confirm the intraoperative findings of e-ICG. The patients were divided into four major groups according to the surgical approach: endonasal, ventricular, vascular and brain tumor procedures. Two different endoscopes were used: a dedicated ICGintegrated endoscope $5.8 \mathrm{~mm}$ in diameter and $19 \mathrm{~cm}$ in length, (Karl Storz, Tuttlingen, Germany) coupled to an IMAGE1 S camera system (Karl Storz, Tuttlingen, Germany) and a Lotta ventriculoscope (Karl Storz, Tuttlingen, Germany) combined to an external optical filter allowing ICG fluorescence visualization.

A $0.2-0.5-\mathrm{mg} / \mathrm{kg}$ intravenous single bolus of ICG was injected by the anesthesiologist during surgery in all groups except for vascular and extended endoscopic endonasal groups in which we used a second injection. Near-infrared excitation of the ICG fluorescence $(780-820 \mathrm{~nm})$ was obtained using a D-light P (Karl Storz) and routine toggling between white light and ICG illumination modes was achieved via a foot switch. In addition to standard images, five visualization enhancement modes, supplied by the IMAGE1 S technology (Clara, Chroma, Clara + Chroma, SPECTRA A and $\mathrm{B}$ ), were utilized and compared during surgery.

Concerning the patient population, the endonasal group included 14 cases: 6 pituitary adenomas (4 non secreting and 2 ACTH secreting macroadenomas), 3 tuberculum sellae meningiomas, 2 clival chordomas, 1 craniopharyngioma, 1 nasopharyngeal carcinoma, and 1 suprasellar epidermoid cyst. All patients underwent an endoscopic endonasal approach. The ventricular group consist of one intraventricular tumor and eight non-communicating hydrocephalus. In all cases, an endoscopic third ventriculostomy (ETV) was performed via a right-sided pre-coronal approach. The vascular group included nine middle cerebral artery aneurysms initially presented without subarachnoid hemorrhage. In one case, there were two simultaneous aneurysms successfully clipped during the same surgery. In all cases, the patients underwent microsurgical clipping via a frontolateral approach. Microscopic (OPMI Pentero operating microscope, Carl Zeiss, Oberkochen, Germany) and endoscopic indocyanine green videoangiographies were contemporary performed to compare pre- and post-clipping images. Brain tumor group included eight intracranial tumors; each patient underwent a microsurgical endoscope assisted resection via different transcranial approaches: two meningiomas (sphenoorbital and frontal convexity), one third ventricle, two frontal and two temporal lobe gliomas, and one parietal lobe metastasis of ovarian carcinoma.

\section{Literature review}

PubMed and Medline databases were searched with combinations of the search terms: "endoscopic indocyanine and third ventriculostomy", "endoscopic indocyanine and transsphenoidal surgery", "endoscopic indocyanine and skull base surgery", "endoscopic indocyanine and aneurysm", "endoscopic indocyanine and brain tumors" and "endoscopic indocyanine in neurosurgery" References contained within these papers were reviewed, including case reports. Overall, 95 studies were identified. Non-English articles, pre-clinical papers, studies including patients treated using microscopicICG technology alone were excluded from our analysis. This resulted in a total of 10 papers which were included in our analysis [16, 17, 19-23, 25-27].

\section{Results}

\section{Case series}

Endoscope-integrated indocyanine green fluorescence procedures were successfully performed in all patients. There were 
no intraoperative surgical complications reported. Postoperative complication occurred in two cases in the endonasal group and they were represented by transient diabetes insipidus. Adverse events due to the use of the dedicated ICG endoscope and/or ICG administration did not occur. ICG fluorescence was visualized on the video screen approximately $10-15 \mathrm{~s}$ after its intravenous injection. Interestingly, a prolonged fluorescence visualization time (the mean of $35 \pm 7 \mathrm{~min}$ ) was possible using the ICG endoscope compared to the operative microscope (15 s) [17]. Specific use and tips related to the surgical approach, the pathology and the visualization enhancement were different in relation to each procedure (Table 1).

Endonasal group Concerning cases with a standard sellar approach, a single $25 \mathrm{mg}$ shot of ICG was injected after the anterior sphenoidotomy: e-ICG significantly enhanced the localization of parasellar segments of both internal carotid arteries (ICAs) (Fig. 1a, b) and superior and inferior intercavernous sinuses before dura opening. Interestingly, during pituitary adenomas removal, the gland remained fluorescent until the end of the procedure so to easily preserve it during tumor excision. SPECTRA-A, among the IMAGE1 S visualization enhancement modes, appeared particularly useful in pituitary gland detection to perform a safe and radical tumor resection
(Fig. 1c-f; Video 1). Operating continuously under ICGmode was also found to be beneficial to localize the bleeding sites under ICG illumination. In the case of extended endoscopic endonasal approach, two shots of $12.5 \mathrm{mg}$ ICG were administered: the first was injected during the nasal step to precisely tailor the nasoseptal flap thus localizing the sphenopalatine artery and its septal branch (Fig. 2). The same doses also allowed subsequential localization of the internal carotid arteries and epidural anatomical structures (dural arteries, superior and inferior intercavernous sinus). A second dose of $12.5 \mathrm{mg}$ of ICG was then injected during tumor removal to precisely localize and check the patency of the neurovascular structures as shown in Fig. 3, during an extended endoscopic endonasal transtuberculum/transplanum approach to remove a tuberculum sellae meningioma (Fig. 4). The same technique was also performed to remove a suprasellar craniopharyngioma (Fig. 5) with a large intraventricular extension (Fig. 6). This way it was possible to identify and divide the recognized vascular structures into the following: submисоsal (sphenopalatine artery and its septal branch, very useful to harvest the nasoseptal flap), underneath the bone (parasellar and paraclival segments of the internal carotid arteries), epidural (dural arteries, superior and inferior intercavernous sinuses) and intradural (optic chiasm perforators, superior hypophyseal arteries, anterior communicating artery, anterior cerebral artery,

Table 1 Specific ICG use and tips related to the surgical approach, the pathology, and e-ICG visualization enhancement in relation to each surgical procedure

\begin{tabular}{|c|c|}
\hline Type of approach & e-ICG use and tips \\
\hline \multirow[t]{2}{*}{ Endonasal } & $\begin{array}{l}\text { Standard sellar approach: suggested use } 1 \text { shot } 25 \mathrm{mg} \\
\text { - Significantly enhanced the localization of parasellar segments of both internal carotid arteries (ICAs) and superior } \\
\text { and inferior intercavernous sinuses before dura opening } \\
\text { - Pituitary gland remained fluorescent until the end of the procedure so to easily preserve it during tumor excision }\end{array}$ \\
\hline & $\begin{array}{l}\text { Extended approach: suggested use } 2 \text { shots } 12.5 \mathrm{mg} \\
\text { It was possible to identify and divide the vascular structures into the following: submucosal (sphenopalatine artery and } \\
\text { its posterior septal branch: very useful to harvest the nasoseptal flap), underneath the bone (clinoidal and petrosal } \\
\text { segment of the internal carotid arteries), epidural (dural arteries, superior and inferior intercavernous sinuses), } \\
\text { intradural (optic chiasm perforators, superior hypophyseal arteries, anterior communicating artery, anterior cerebral } \\
\text { artery, pituitary gland and stalk) }\end{array}$ \\
\hline Ventricular & $\begin{array}{l}\text { Suggested use: } 1 \text { shot } 25 \mathrm{mg} \\
\text { - Clearly showed the course of the basilar and posterior cerebral arteries, and it was very useful to determine the safest } \\
\text { site for ventriculostomy } \\
\text { - Concerning the third ventricle tumor, ICG administration enhanced visualization of tumor margins and was useful } \\
\text { to identify proper sites to biopsy }\end{array}$ \\
\hline Vascular & $\begin{array}{l}\text { Suggested use: } 2 \text { shots } 12.5 \mathrm{mg} \\
\text { - Aneurysm morphology, perforating vessels preservation } \\
\text { - Excellent visualization window for fluorescence angiography during the pre- and post-clipping steps of surgery }\end{array}$ \\
\hline Brain tumors & $\begin{array}{l}\text { Suggested use: } 1 \text { shot } 25 \mathrm{mg} \\
\text { Intraaxial: } \\
\text { Identification of the tumor based on the differences in fluorescence intensity before surgical removal due to } \\
\quad \text { blood-brain barrier disruption } \\
\text { Extraaxial: } \\
\text { Useful information on the tumoral and peritumoral vessels. Post-resection, the patency of the peritumoral vessels could } \\
\text { be assessed }\end{array}$ \\
\hline
\end{tabular}




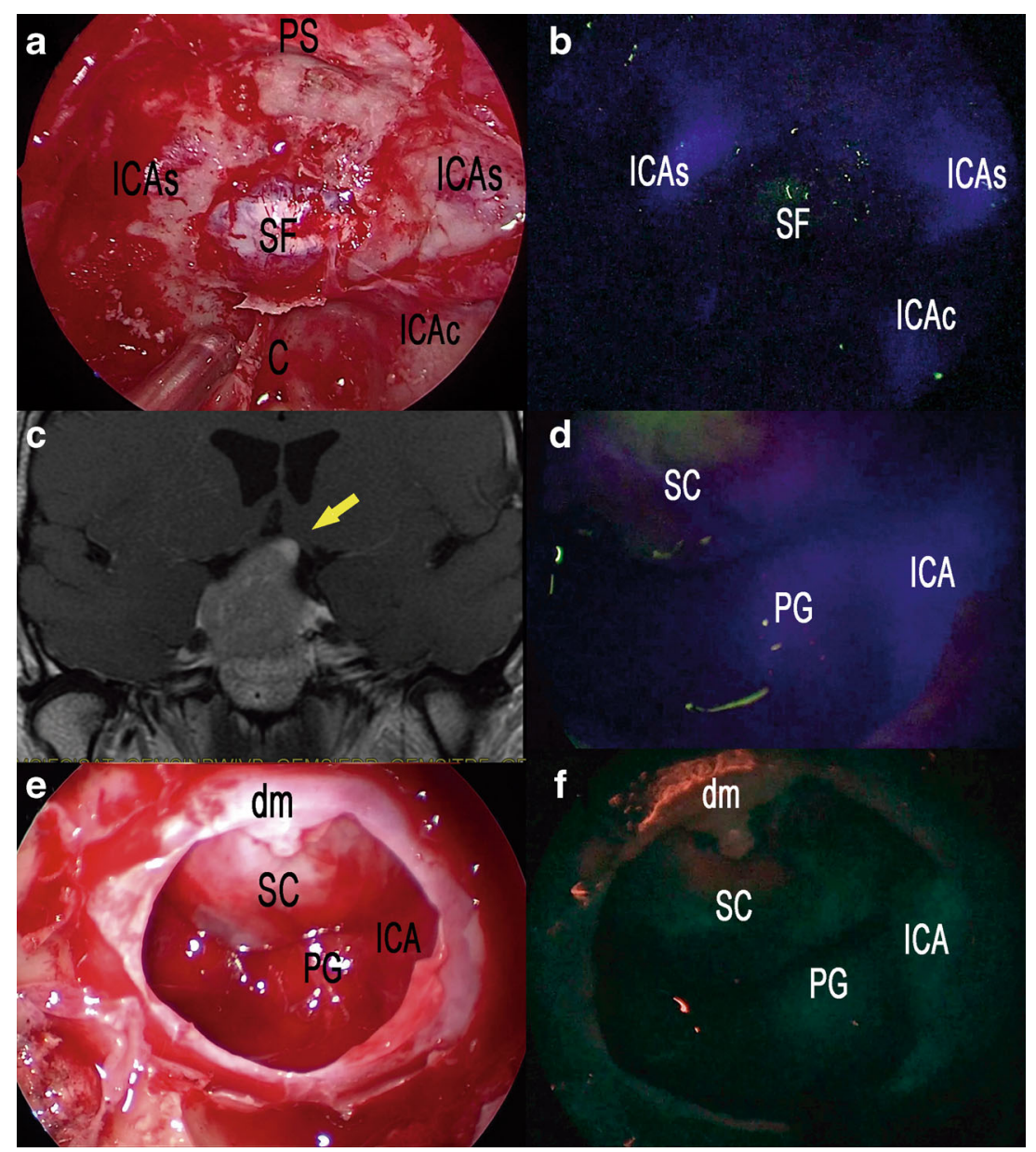

Fig. 1 Standard endoscopic endonasal approach to the sella. a The photo demonstrates the surgical field during sphenoidal step of the approach and the appearance under white light of the posterior wall of the sphenoid sinus. b The same surgical field as in a under near-infrared light after injection of ICG. c Post-contrast T1-weighted brain magnetic resonance imaging (MRI), coronal view, showing the pituitary macroadenoma with elevation and compression of the optic chiasm. The yellow arrow shows the position of the pituitary gland. d ICG fluorescence highlighting

pituitary gland and stalk). Fluorescence confirmed the vascular anatomical information acquired through the neuronavigation vascular structures within the intradural step of the approach. e The photo demonstrates the same field of view and the appearance of sellar area under white light. $\mathbf{f}$ The same surgical field under near-infrared light after injection of ICG using SPECTRA-A mode. SC suprasellar cistern, $P G$ pituitary gland, $S F$ sellar floor, $C$ clivus, $I C A$ internal carotid artery, $I C A s$ parasellar segment of the internal carotid artery, ICAc clival segment of the internal carotid artery, $d m$ dura mater, $P S$ planum sphenoidale

system, specially the position of the pituitary gland during all procedures (Fig. 2; Video 1). However, in this group, it was

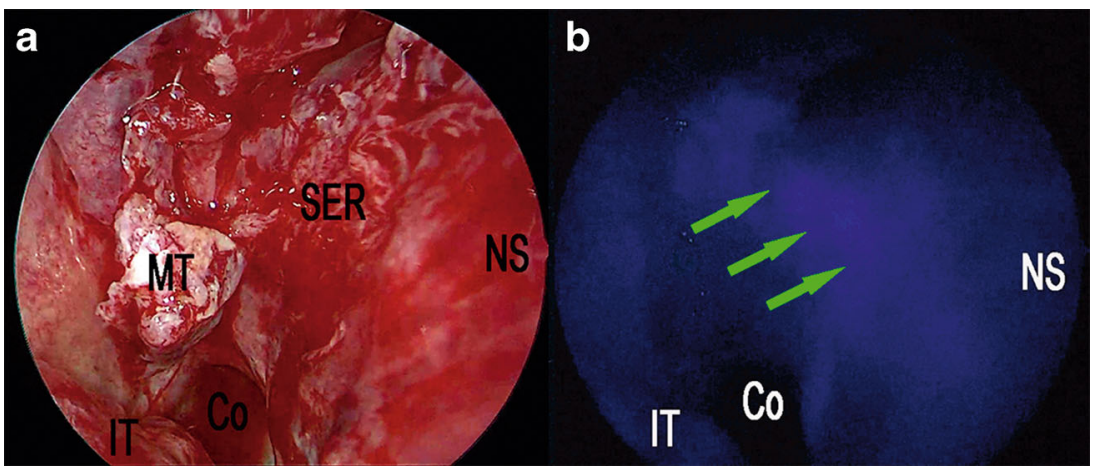

Fig. 2 Nasal step of extended endoscopic endonasal approach (a). Right nostril, harvesting of a pedicled nasal septal flap based on the posterior nasal septal artery (b). The same surgical field under near-infrared light after injection of ICG fluorescence highlighting vascular structures within nasal septum; the green arrows show the submucosal position of the posterior nasal septal artery. Co choana, IT inferior turbinate, $M T$ middle turbinate, SER sphenoethmoid recess, NS nasal septum 


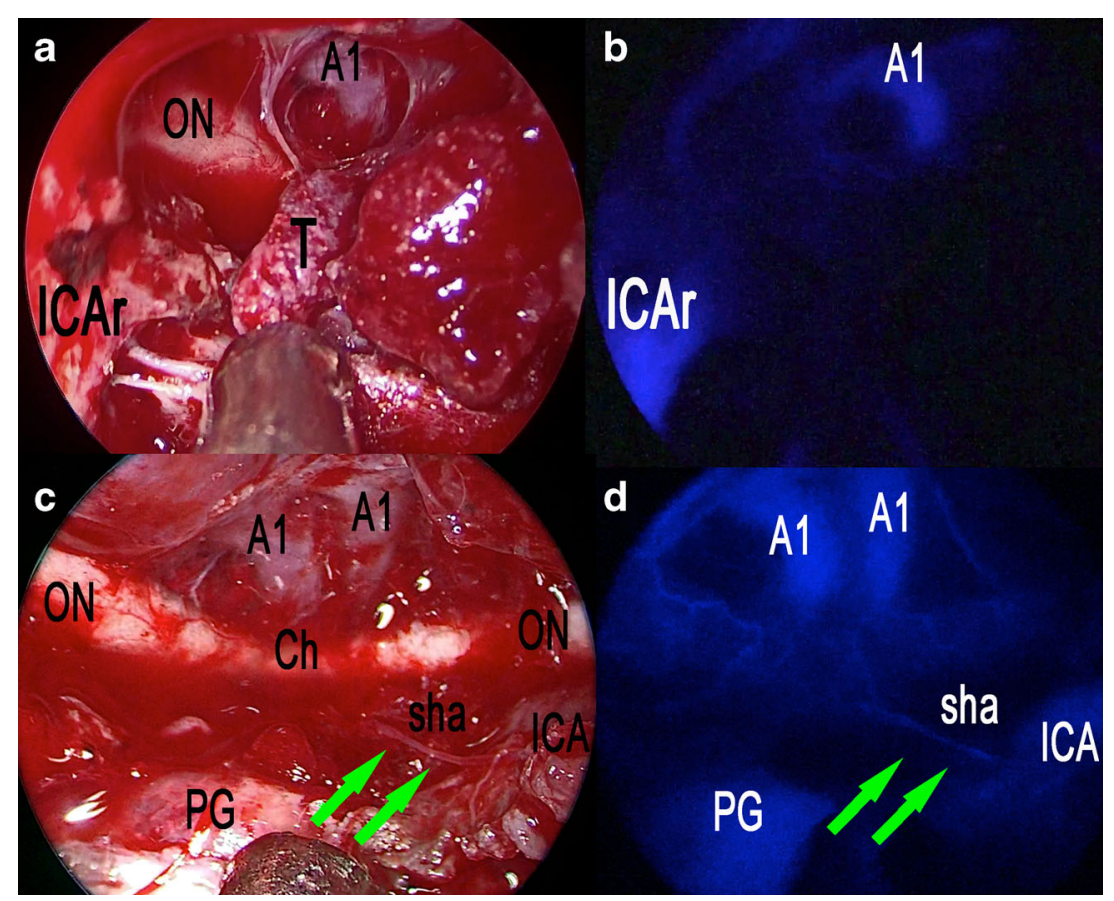

Fig. 3 Extended endoscopic endonasal transtuberculum/transplanum approach, removal of a tuberculum sellae meningioma. a The photo demonstrates the surgical field during tumor removal step and the appearance under white light. b The same surgical field as in a under near-infrared light after injection of ICG. $\mathbf{c}$ The photo demonstrates the surgical field after the complete excision of the tumor and the appearance under white light. $\mathbf{d}$ The same surgical field as in $\mathbf{c}$ under near-infrared light after injection of ICG. $O N$ optic nerve, $A l$ anterior cerebral artery, $T$ tumor, $I C A r$ right internal carotid artery, $C h$ optic chiasm, $P G$ pituitary gland, sha superior hypophyseal artery; green arrows show the course of the superior hypophyseal artery
Fig. 4 Post-contrast T1-weighted brain MRI, coronal and sagittal view, showing preoperative $(\mathbf{a}, \mathbf{b})$ and postoperative $(\mathbf{c}, \mathbf{d})$ images of a tuberculum sellae meningioma

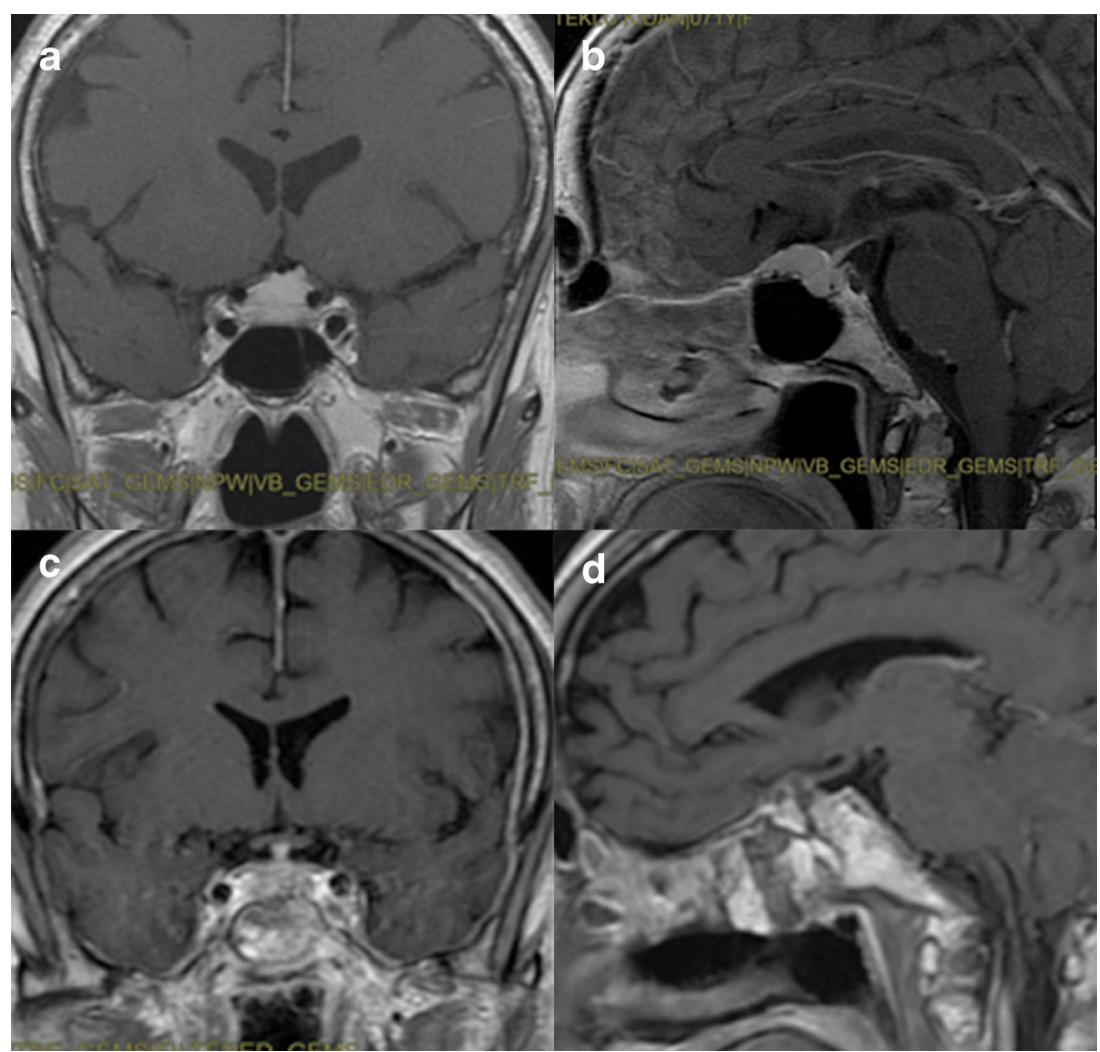




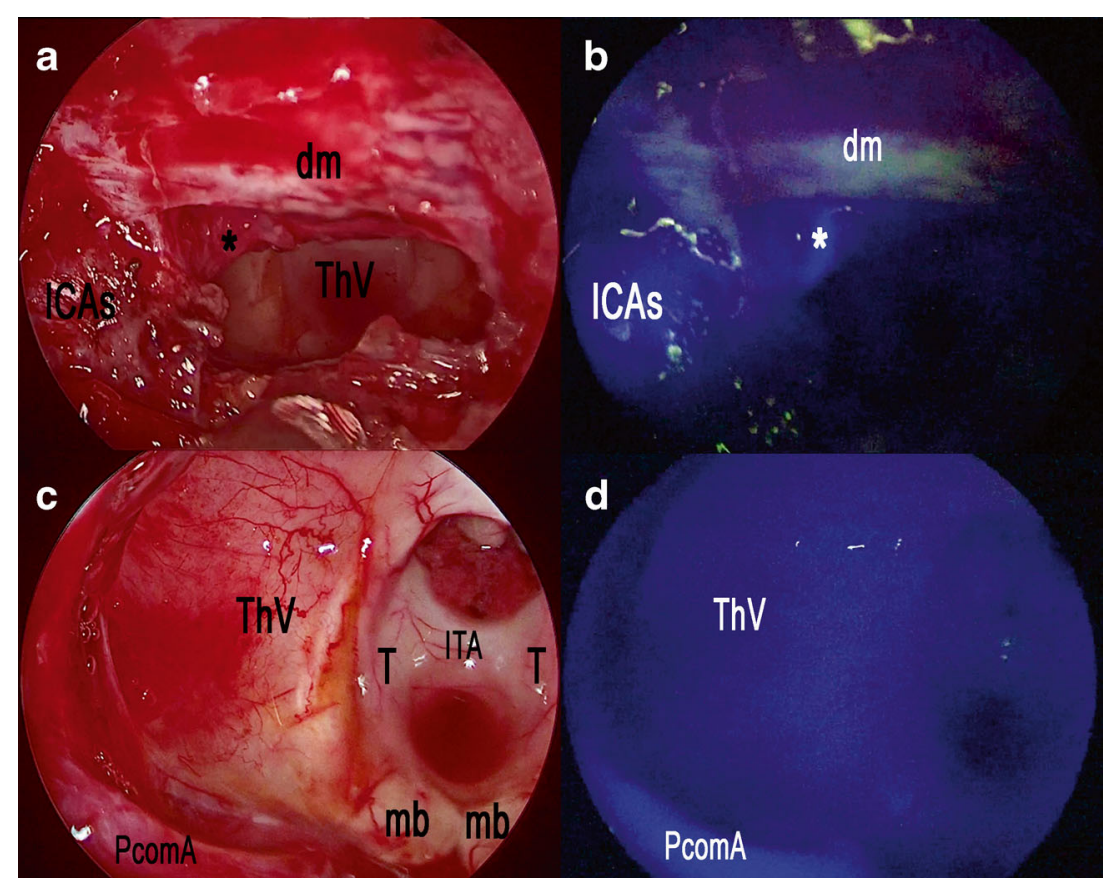

Fig. 5 Extended endoscopic endonasal transtuberculum/transplanum approach, removal of a suprasellar craniopharyngioma. a The photo demonstrates the surgical field during the removal of the tumor and the appearance under white light. b The same surgical field as in $\mathbf{c}$ under nearinfrared light after injection of ICG. c The photo demonstrates the surgical field after the complete removal of the tumor and the appearance under

mandatory to ensure a clear and bloodless operative field before using ICG to avoid "diffuse" and "false positive" fluorescence visualization.

Ventricular group In all cases, a single $25 \mathrm{mg}$ bolus of ICG was injected when the third ventricle floor was under vision, prior to ventriculostomy. While performing such procedure, fenestration of the third ventricle floor should be performed between the mammillary bodies and the infundibular recess, at the most transparent site (tuber cinereum). Under white light visualization, the localization of the typically invisible basilar artery is critical to avoid vessel injury during the procedure and the fenestration should be made anterior to the artery white light. $\mathbf{d}$ The same surgical field as in $\mathbf{c}$ under near-infrared light after injection of ICG. ICAs parasellar segment of the internal carotid artery, asterisk superior hypophyseal artery, $d m$ dura mater, ThV third ventricle, $T$ thalamus, ITA interthalamic adhesion, $P$ comA posterior communicating artery, $m b$ mammillary body

complex. In all cases, a ventriculoscope coupled with a dedicated external optical filter allowing transmission of ICG fluorescence clearly showed the course of the basilar and posterior cerebral arteries and it was very useful to determine the site for ventriculostomy ensuring total safety (Fig. 7; Video 1). Concerning the case of the third ventricle tumor, histology showed a pilocytic astrocytoma and ICG administration enhanced visualization of tumor margins and was useful to identify proper sites to biopsy as already demonstrated by Tsuzuki et al. [22].

Vascular group In such group, two doses of ICG were administered: one dose of $12.5 \mathrm{mg}$ of ICG before aneurysm
Fig. 6 Post-contrast T1-weighted brain MRI, coronal (a) and sagittal (b) views, showing a suprasellar craniopharyngioma with a large third ventricular extension

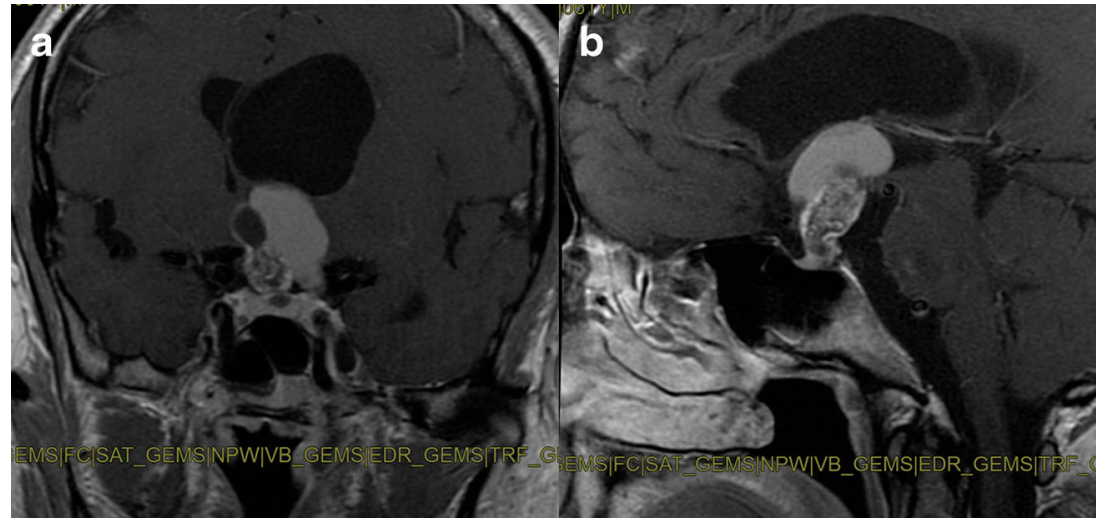




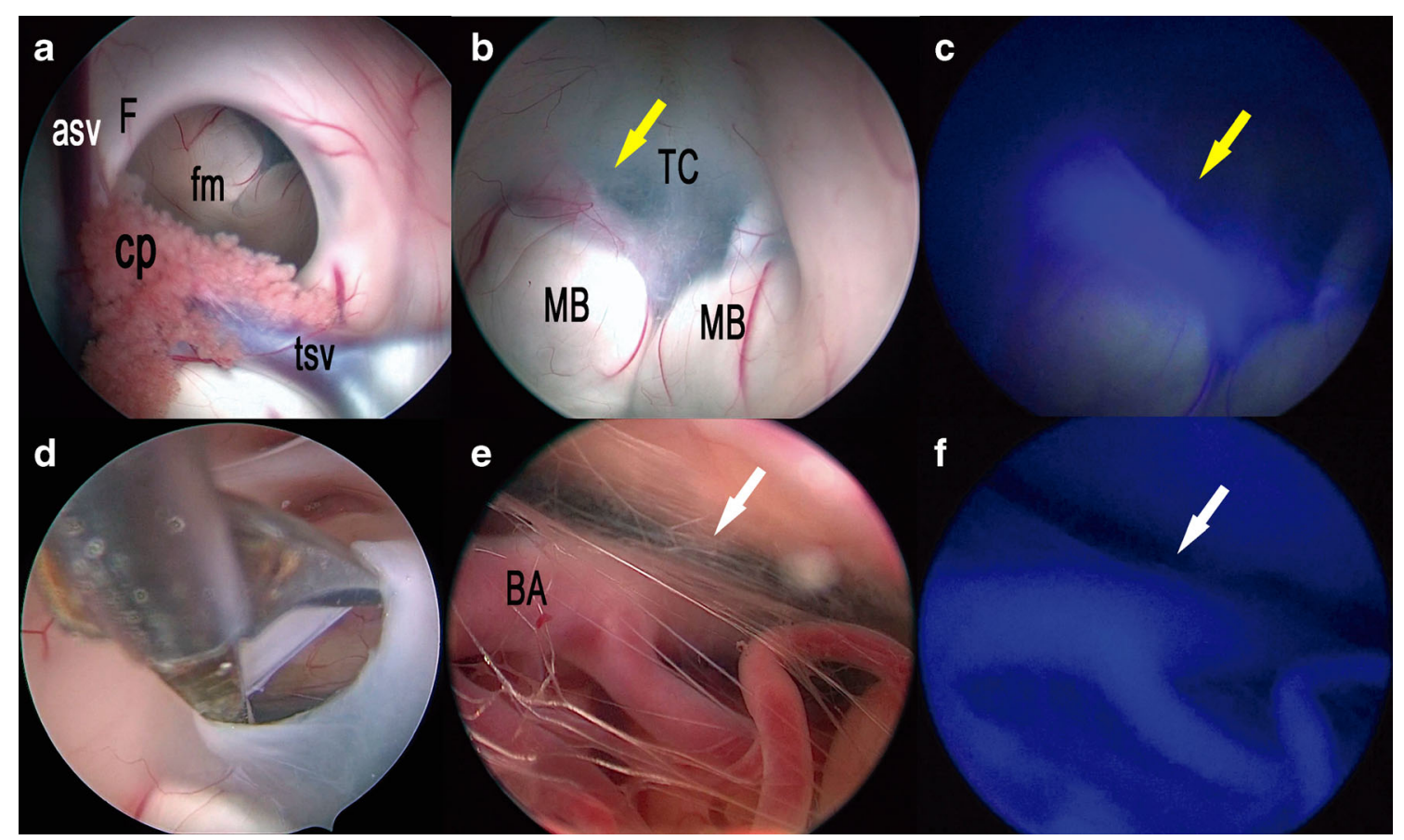

Fig. 7 Right frontal endoscopic third ventriculostomy. a The photo demonstrates the surgical field in the lateral (a) and third (b) ventricles under white light. $\mathbf{c}$ The same surgical field as in $\mathbf{b}$ under near-infrared light after injection of ICG. d The photo demonstrates the surgical field during the opening of the third ventricle floor in the area of the tuber cinereum and the endoscopic exploration of the interpeduncular cistern (e) under white light. f The same surgical field as in e under near-infrared light after injection of ICG. asf anterior septal vein, $c p$ choroid plexus, $f m$ foramen of Monro, $F$ fornix, $t s v$ thalamostriate vein, $M B$ mammillary body, $B A$ basilar artery; yellow arrow shows the course of the posterior cerebral artery; white arrow shows the course of the basilar artery

parietal approach. Employing the e-ICG approach in intrinsic brain tumor cases located within the cortical surface enabled the identification of the tumor based on the differences in fluorescence intensity before surgical removal due to bloodbrain barrier disruption. Figure 10 shows the intraoperative findings during spheno-orbital meningioma removal via a left pterional approach. During extraaxial tumor resection, e-ICG provided useful information on the tumoral and peritumoral vessels. Post resection, the patency of the peritumoral vessels could be assessed and was especially useful for the veins.

\section{Literature review}

Among 10 papers considered, 4 were included within the endonasal field, 2 within the ventricular field, 3 within the vascular field and 1 within the brain tumor field. All included studies are summarized in Table 3.

Concerning the endonasal field, the first experience was reported in 2012 by Litvack et al. [20] in a prospective study. The paper analyzes 16 patients (but 1 patient was excluded following discovery of a dye cross-allergy) undergoing endoscopic endonasal surgery for benign pituitary lesions using a standard endoscope with a near-infrared light source and an excitation wavelength filter. A dose of $12.5-25 \mathrm{mg}$ was injected in bolus two or three times: first during the nasal step, a second injection was sometimes used during tumor
Brain tumor group In all cases, a single $25 \mathrm{mg}$ bolus of ICG was injected after opening of the dura and before tumor removal to assess tumor margins due to blood-brain barrier disruption and to visualize tumor and peritumor vascularization. Figure 9 presents the intraoperative findings during a parietal lobe metastasis of ovarian carcinoma removal via a right 


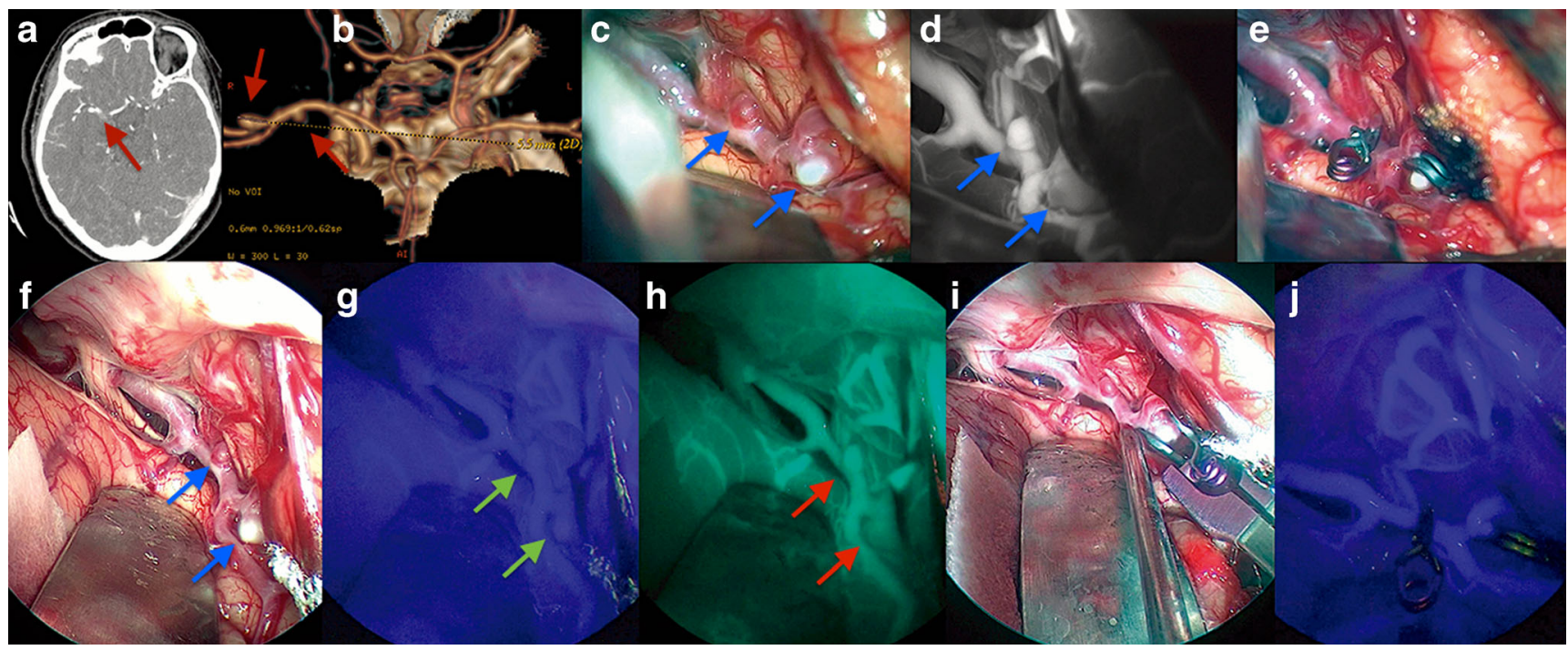

Fig. 8 Intraoperative findings during two middle cerebral artery aneurysms clipping cases via a right frontolateral approach. Highresolution computer tomography (CT) angiography and CT-based 3D reconstruction of two middle cerebral artery aneurysms $(\mathbf{a}, \mathbf{b})$; red arrows show the position of the aneurysms. c Right Sylvian fissure opening under microscopic view and white light; blue arrows show the position of the aneurysms. d The same surgical field as in $\mathbf{c}$ under indocyanine microscopic integrated view; blue arrows show the position of the aneurysms. e Clipping of the two middle cerebral aneurysms under microscopic view and white light. f Same case, right
Sylvian fissure opening under endoscopic assisted view and white light; blue arrows show the position of the aneurysms. $\mathrm{g}$ The same surgical field as in $\mathbf{f}$ under near-infrared light after injection of ICG; green arrows show the position of the aneurysms. $\mathbf{h}$ The same surgical field as in $\mathbf{g}$ under near-infrared light after injection of ICG using SPECTRA-A mode; red arrows show the position of the aneurysms. i Clipping of the two middle cerebral aneurysms under endoscopic assisted view and white light. $\mathbf{j}$ Post-clipping step of the two middle cerebral aneurysms under endoscopic assisted view and near-infrared light after injection of ICG

opening. E-ICG assisted to confirm anatomical landmarks in real time and to preserve blood supply of the optic nerves and pituitary. The internal carotid artery (ICA) was identified through the dura mater and within the sphenoid sinus, if covered by thin bone.

Inoue et al. reported in 2015 [25] their experience concerning a multimodal assistant systems that generates a fusion model of preoperative three-dimensional (3D) computed tomography and magnetic resonance imaging (MRI) along with endoscopy with ICG fluorescence. They studied 10 patients who underwent endonasal surgery for sellar or sphenoidal sinus tumors. The authors used a $0^{\circ}$ dedicated telescope (5.8 $\mathrm{mm}$ in diameter, $19 \mathrm{~cm}$ in length) and injected a single

Table 2 General aspects: pros and cons of e-ICG use

Pros

Cons

FDA approval: low toxicity and rapid elimination through bile excretion

Fluorescence visualization window can be seen up to $42 \mathrm{~min}$, much more than with the operative microscope.

Versatility of such tool in different neurosurgical scenarios and complex vascular environments

Penetrate tissue up to $3 / 10 \mathrm{~mm}$ below the surface raises the possibility of identifying deeper lying vascular structures masked under various tissues There is still room for future technical developments.
Dedicated endoscope with a larger diameter $(5.8 \mathrm{~mm})$

External ICG filter does not allow the same image quality observed in the other procedures with a dedicated integrated ICG endoscope.

Unavailability of angled telescopes limits direct operative view of blind corners.

Very clear surgical field is mandatory in order to expose the desired vascular structure without the risk of false visual perception.

The lack of simultaneous visualization of fluorescent and non-fluorescent images in parallel 
Fig. 9 The intraoperative findings during a parietal lobe metastasis of ovarian carcinoma removal via a right parietal approach. a Microscopic view before tumor removal under white light; yellow arrow shows the necrotic part of the lesion while the green arrows show the blood-brain barrier disruption. b The same surgical field as in a under indocyanine microscopic integrated view; yellow arrow shows the necrotic part of the lesion while the green arrows show the blood-brain barrier disruption. c The same surgical field as in $\mathbf{b}$ under endoscopic assisted view and near-infrared light after injection of ICG; yellow arrow shows the necrotic part of the lesion while the green arrows show the bloodbrain barrier disruption

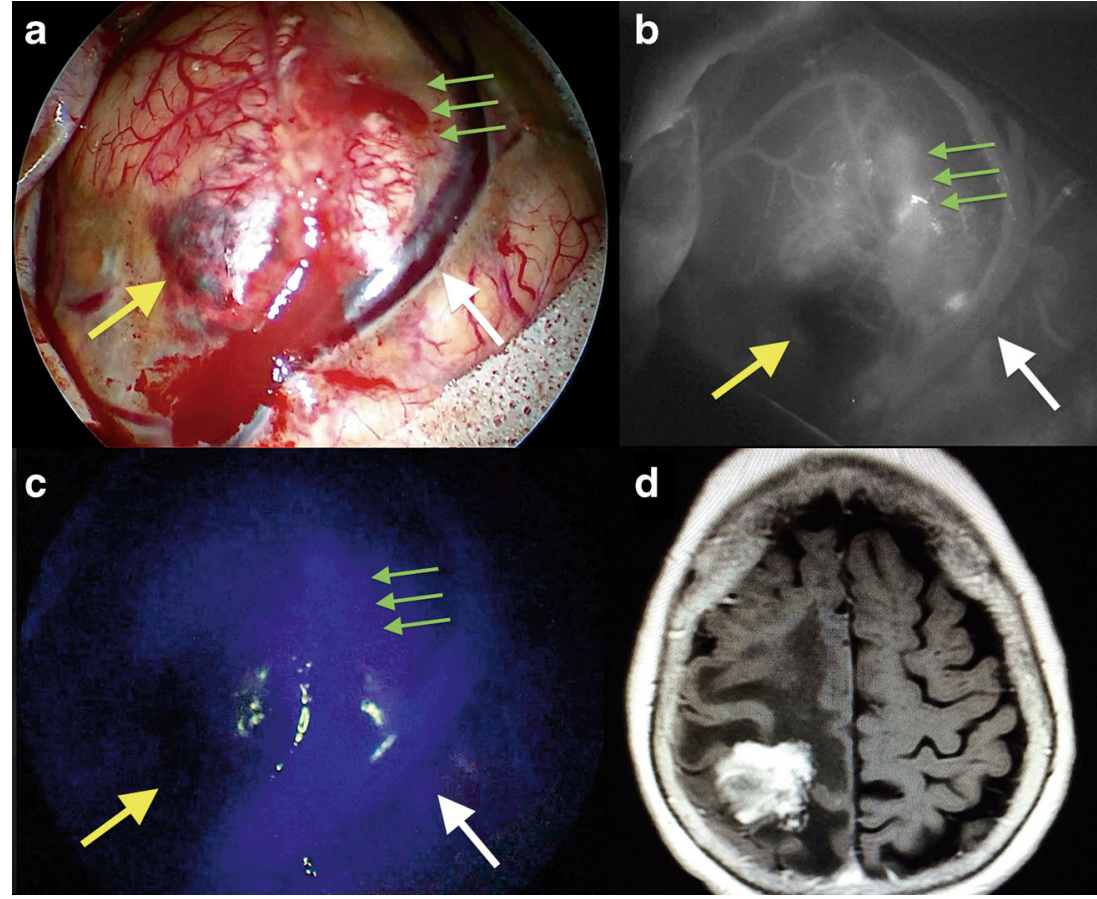

bolus of $12.5 \mathrm{mg}$ of ICG. They reported that e-ICG resulted to be superior to the neuronavigation system to identify the internal carotid artery before opening the sellar floor.

Finally, Simal Juliàn et al. [21] reported in 2016 their experience, demonstrating that e-ICG provides a superior ability to detect the margins of the ICA compared with the Doppler technique and also provides enhancement of the artery through the bone of the skull base without the need for drilling. They reported two illustrative cases using an adapted $0^{\circ}$ optical module; ICG dose and injection timing were not reported. The authors underlined two aspects: exposure of parasellar segments and paraclival segments of ICAs (intense fluorescent enhancement) before skull base drilling and then during the intradural step in which tumor resection, especially very closely to the ICA, was assisted by fluorescence under ICG-mode. The main limitations indicated by the authors were availability of only $0^{\circ}$ optic lenses, lack of quantization of bone thickness to visualize ICA and impossibility to see conventional images and images under ICG-mode simultaneously.

Concerning the ventricular neuroendoscopic surgery field, the first experience was reported in 2013 by Wachter et al. [23]. The study included 11 patients with noncommunicating hydrocephalus undergoing endoscopic third ventriculostomy (ETV). The authors used a prototype of a video-integrated $0^{\circ}$ rigid endoscope with a diameter of $5.8 \mathrm{~mm}$ that replaced a standard ventriculoscope only in the step of the opening of the third ventricle floor. In this step, a

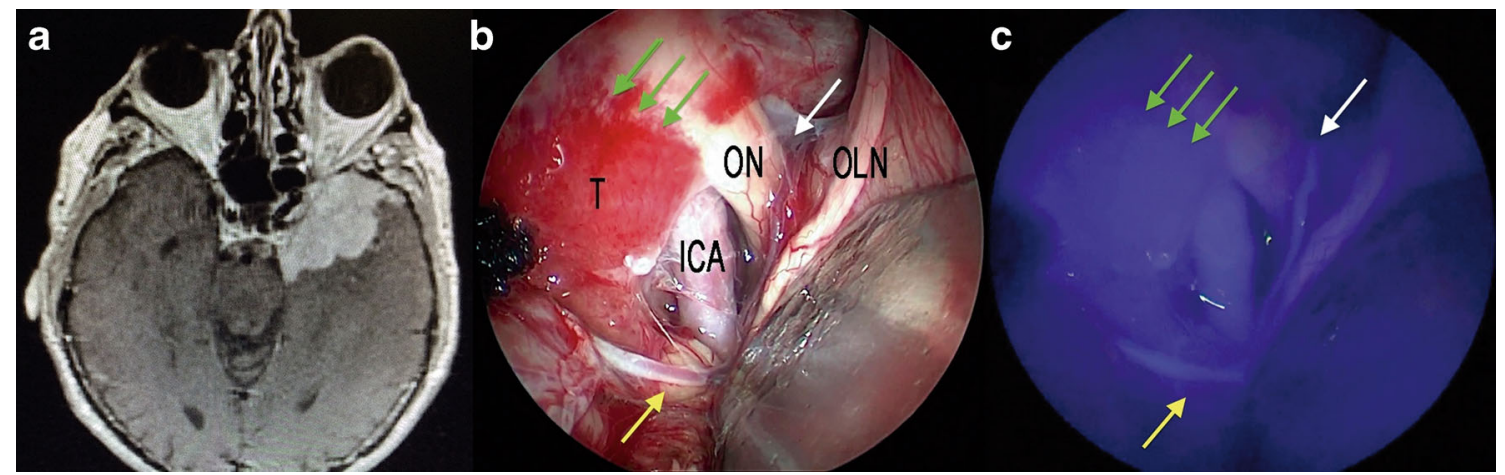

Fig. 10 Intraoperative findings during spheno-orbital meningioma removal via a left pterional approach. Post-contrast T1-weighted brain MRI, axial view, showing the spheno-orbital meningioma extension. b Endoscopic assisted view showing the subfrontal exposure if the tumor under white light (a) and near-infrared light (c) after injection of ICG; yellow arrow shows a branch of the middle cerebral artery while the green arrows show the dural attachment of the lesion; the white arrow shows the a perforating artery over the left optic nerve 
Table 3 Review of the literature focusing on the recent case series of patients treated via an endoscopic integrated indocyanine green fluorescence technique

\begin{tabular}{|c|c|c|c|c|}
\hline Author, year & $\begin{array}{l}\text { Number } \\
\text { of patients }\end{array}$ & ICG endoscope & ICG dose and timing & Applications and advantages \\
\hline
\end{tabular}

\begin{tabular}{|c|c|c|c|}
\hline - Litvack ZN, 2012 & 15 & $\begin{array}{l}\text { Custom telescope } \\
\text { with a selectable } \\
790 \mathrm{~nm} \text { filter }\end{array}$ & $\begin{array}{l}12.5-25 \mathrm{mg} \text { (bolus) } \times 2 \text { or } 3 \text {, } \\
\text { after standard sellar approach } \\
\text { eventually during tumor } \\
\text { exposure and a final injection } \\
\text { after tumor removal }\end{array}$ \\
\hline - Hide T, 2015 & 38 & $\begin{array}{l}0^{\circ} \text { telescope } \\
\quad(5.8 \mathrm{~mm} / 19 \mathrm{~cm})\end{array}$ & $\begin{array}{l}12.5 \mathrm{mg} \text { (bolus), after sphenoid } \\
\text { sinus opening }\end{array}$ \\
\hline - Inoue A, 2015 & 10 & $\begin{array}{l}0^{\circ} \text { telescope } \\
\quad(5.8 \mathrm{~mm} / 19 \mathrm{~cm})\end{array}$ & $12.5 \mathrm{mg}$ (bolus), on demand \\
\hline - Simal Juliàn JA, 2016 & 2 & $\begin{array}{l}\text { Adapted } 0^{\circ} \\
\text { optical module }\end{array}$ & $\mathrm{n} / \mathrm{a}$ \\
\hline
\end{tabular}

\section{Endonasal}

- Endoscopic transsphenoidal surgery for benign pituitary lesions

- To distinguish pituitary tumors from normal tissue and to visually identify areas of dural invasion

- Standard and extended endoscopic transsphenoidal surgery

- To confirm anatomical landmarks in real-time and to preserve blood supply of the optic nerves and pituitary

- Endoscopic transsphenoidal surgery for sellar or intrasphenoidal sinus tumors

- To display in real-time the anatomical relationships between the tumor and surrounding structures

- Skull base expanded endonasal surgery

- To localize ICA before sellar drilling and during the intradural exploration

Ventricular

- Wachter D, 2013

11

Prototype of $0^{\circ}$ rigid endoscope (5.8 $\mathrm{mm}$ in diameter)

- Tsuzuki S, 2013

3

$0^{\circ}$ telescope $(5.8 \mathrm{~mm} / 19 \mathrm{~cm})$

- Bruneau M, 2012 1 $0^{\circ}(5.8 \mathrm{~mm} / 19 \mathrm{~cm})$ NIR-optimized endoscope

- Mielke D, 2014 endoscope (5.8 $\mathrm{mm}$ in diameter)

- Yoshioka H, 2015
$0.2-0.5 \mathrm{mg} / \mathrm{kg}$, after exposure of 3 rd ventricle floor

$12.5 \mathrm{mg}$ (bolus) $\times 2$ $7.5+12.5 \mathrm{mg}$
$20 \mathrm{mg}$ (bolus) $\times 4$, after aneurysm dissection and after clipping

$0.2-0.5 \mathrm{mg} / \mathrm{kg}$, before and after clip placement

$\mathrm{n} / \mathrm{a}$, before and after clip placement
- Endoscopic third ventriculostomy

- To visualize the basilar artery and its perforators to reduce the risk of vascular injury

- Endoscopic biopsy of intraventricular tumors

- To consider the most appropriate region for biopsy

Vascular

- Clipping of unruptured anterior communicating artery aneurysm

- To obtain additional information regarding aneurysm occlusion and patency of parent and branching vessels and small perforating arteries

- Clipping of unruptured and ruptured cerebral aneurysms and comparison with $\mathrm{m}$-ICG

- To visualize hidden regions of the microsurgical field thanks to longer fluorescence, different and enlarged viewing angles compared with m-ICG

- Clipping of cerebral aneurysms

- To see in the dead angles of microscopic fluorescence video angiography for preventing unexpected occlusion of arteries around aneurysms 
Table 3 (continued)

\begin{tabular}{lcccc}
\hline Author, year & $\begin{array}{l}\text { Number } \\
\text { of patients }\end{array}$ & ICG endoscope & ICG dose and timing & Applications and advantages \\
\hline & 7 & $\begin{array}{c}0^{\circ} \text { endoscope } \\
(5.8 \mathrm{~mm} / 19 \mathrm{~cm})\end{array}$ & $\begin{array}{c}5 \mathrm{mg}, \text { after identification } \\
\text { of tumor feeding } \\
\text { artery }\end{array}$ & $\begin{array}{l}\text { Skull base tumors } \\
\text { - Recurrent skull base cancer } \\
\text { - To evaluate the blood supply to the } \\
\text { tumor and to administrate superselective } \\
\text { intraarterial chemotherapy }\end{array}$ \\
\hline
\end{tabular}

$n / a$ not available

dose of $0.2-0.5 \mathrm{mg} / \mathrm{kg}$ of ICG was injected. No adverse events related to ICG administration occurred. Except a case of technical failure, e-ICG facilitated the identification of the basilar tip and its branches especially in the presence of an opaque third ventricular floor $(n=5)$.

Tsuzuki et al. [22] reported, in 2013, three cases of hydrocephalus secondary to intra- and periventricular tumors. All patients underwent endoscopic transventricular biopsy and ETV. The authors used an ICG telescope $5.8 \mathrm{~mm} / 19 \mathrm{~cm}$ in addition to a flexible endoscope. The ICG dose was $12.5 \mathrm{mg}$, administered in single boli twice for two cases and single boli of $7.5+12.5 \mathrm{mg}$ in the latter cases. There were no side effects related to ICG administration. E-ICG helped to identify the tumor margins and to detect the differences of intratumoral ICG accumulation so to consider an adequate region for tumor biopsy.

In the neurovascular field, the first application of e-ICG was reported in 2012 by Bruneau M et al. [16]. This technique was applied during a case of unruptured anterior communicating artery aneurysm for which the patient was scheduled to undergo a conventional microsurgical clipping procedure. The endoscopic used was a $0^{\circ}(19 \mathrm{~cm}, 5.8 \mathrm{~mm})$ NIR-optimized endoscope, with a built-in optical filter. Interestingly, the integrated filter did not suppress the microscopic illumination light which inhibited the microscopic and endoscopic ICGmode to be used in tandem. A 20-mg bolus of ICG was administered twice following microscopic assisted dissection, and two boli were subsequently administered after clipping (for microscopic and endoscopic ICG-mode, respectively). E-ICG offered high-resolution, panoramic view, and consequently, additional information about aneurysm occlusion and patency of parent and perforating vessels.

The most relevant paper concerning the vascular group was reported by Mielke et al. [17] in 2014. The same group pioneered the use of e-ICG in ventricular neuroendoscopic surgery field [23]. This study represents to date the largest sample series including 26 patients with unruptured and ruptured cerebral aneurysms in which the authors compared the information given by $\mathrm{m}-\mathrm{ICG}$ and e-ICG. They used a prototype of a video-integrated $0^{\circ}$ rigid endoscope with a $5.8-\mathrm{mm}$ diameter. ICG was administered before and after clip placement with the dose of $0.2-0.5 \mathrm{mg} / \mathrm{kg}$. No adverse events and technical failures related to e-ICG occurred. Compared with $\mathrm{m}-\mathrm{ICG}$, e-ICG provided more information in 11 of the 26 operations $(42.3 \%)$, mostly due to longer duration of fluorescence (10 times longer), different viewing angles, and closer enlarged view of the vessels and aneurysm.

Yoshioka et al. [27] reported in 2015 nine cases of cerebral aneurysms underwent microsurgical clipping with e-ICG assistance. This series includes three patients already considered by the same group in a paper reported in 2012 by Nishiyama $Y$ et al. [18]. The authors used $30^{\circ} / 70^{\circ}$ rigid endoscopes with 4 $\mathrm{mm}$-diameter and a cutoff filter to visualize fluorescence. ICG dose was not reported; however, the given dose was administered pre- and post-clipping. No complications related to additional use of e-ICG were reported. In one case, an adequate endoscope position during surgery was difficult due to limited space. E-ICG appeared helpful to evaluate the blood flow in perforating arteries behind parent arteries or aneurysm itself.

In the brain tumor field, e-ICG applications were restricted to a single case only. Yokoyama et al. [26] in 2016 reported their experience with e-ICG for superselective intra-arterial chemotherapy in recurrent skull base tumors. The authors used a $0^{\circ}$ endoscope $(5.8 \mathrm{~mm} / 19 \mathrm{~cm})$ and a dose of $5 \mathrm{mg}$ of ICG. They performed an angiography after identification of a branch of a possible tumor feeding artery. In this phase, e-ICG was additionally used for confirmation of arteries supplying tumors and to decide about the administration of anticancer drug. Among visualization supported modules, SPECTRA-A mode revealed the blood supply to tumors more accurately than standard mode. Interestingly, the authors observed an ICG penetration within the tissue up to $10 \mathrm{~mm}$.

\section{Discussion}

During the last years, indocyanine green angiography has become a convincing technology in several neurosurgical fields to limit the morbidity and improve clinical outcomes [28-32]. In our experience, the enhanced vascular anatomical visualization during various endoscopic procedures was useful in all clinical cases presented in the study to visualize arterial, capillary and venous structures that can be precisely observed intraoperatively in real time. The use of such tool 
demonstrated great versatility in different surgical scenarios and complex vascular environments by the main advantage of endoscopy: enhanced visualization, better magnification of the areas of interest and dynamic vision "around the corner".

As a matter of fact, the results of our systematic literature review and our institutional experience allowed to highlight few points.

The main factor is represented by a prolonged ICG fluorescence visualization compared to the traditional one visualized via the fluorescence mode of the operating microscope. Such unique features open new and extraordinary applications beyond the use of $\mathrm{m}-\mathrm{ICG}$ in different surgical fields due to the longer duration of fluorescence, 10 times more [17] and up to $35 \pm 7 \mathrm{~min}$ in our experience using a single ICG administration, i.e., during pituitary adenomas surgery. Indeed, the pituitary gland remained fluorescent until the end of the procedure so to safely preserve it during tumor removal [20]. Furthermore, the ICG depth of light energy showed the singular and extraordinary possibility of penetration within the tissues, thus identifying vascular structures masked under different anatomical layers up to 3-10 mm below the tissues' surface $[26,33]$. Using such intrinsic propriety during endoscopic procedures, it was possible to enhance different vascular structures depending on the surgical area of interest: the nasal mucosa to localize the posterior nasoseptal branch of the sphenopalatine artery in order to raise vascularized nasal flaps during extended endoscopic endonasal approaches; the bone to visualize the parasellar and paraclival segments of the internal carotid artery and the dura mater to localize the superior and inferior intercavernous sinuses during endoscopic endonasal approaches; and the other application in neuroendoscopy allowed to see beyond the third ventricular floor in order to identify the position of the basilar and posterior cerebral arteries before performing a third ventriculostomy [23] (Video 1).

The other significant aspect of our pilot study is to report our experience on the new alternative endoscopic technique applications of ICG apart from the vascular field, such as endoscopic endonasal, ventricular and brain tumor surgeries. The idea was to demonstrate the versatility of such tool in multiple surgical scenarios in which the use of e-ICG may complement other intraoperative enhanced visualization techniques related to regional blood flow and capillary density assessment relative to variations in tissue metabolic activity (i.e., fluorescence-guided surgery with 5-aminolevulinic acid or fluorescein) [20]. In such new fields, the use of e-ICG will open new surgical strategies for skull base reconstruction techniques, i.e., the harvesting of vascularized nasoseptal flaps tailoring the inclusion of the septal branch of the sphenopalatine artery. Indeed, the powerful possibility of eICG to enhance the "individual anatomy" of vascular structures in real time during the surgical procedures represents an important complement to help achieve the highest levels of safety while minimizing neurologic injury. In this regard, the visualization of the basilar and posterior cerebral arteries during third ventricular surgery is the key point to determine the correct site for ventriculostomy ensuring total safety.

Another aspect is the possibility to detect blood-brain barrier disruption. Employing the e-ICG during intrinsic brain tumor surgery located within the cortical surface enabled the identification of the tumor based on the differences in fluorescence intensity, while in extraaxial tumors, the e-ICG open the possibility to localize peritumor arteries and to the preserve normal anatomy.

Despite the many viable and extraordinary features of eICG, such tool requires further development. A smaller diameter endoscope may be more useful to a relative $5.8 \mathrm{~mm}$ in diameter telescope used in the present study which could improve surgical dexterity and the surgical freedom [34] especially during endoscopic endonasal and ventricular surgery in which the operative field is extremely confined. Another limitation of the endoscope is the unavailability of variable angled scopes to enable direct operative view of blind corners. One more significant limitation is the absence of a dedicated ICG-integrated endoscope with a working channel and adequate diameter for ventricular procedures. We note that a standard ventriculoscope, coupled with an "external" ICG optical filter, does not provide the same image quality exhibited in procedures using an integrated ICG endoscope. Another critical point is the need to obtain a very clear surgical field especially during endoscopic endonasal surgery in order to expose the desired surgical region without the risk of false visual perception due to the bleeding/oozing that can create "false" vascular structures. Indeed during e-ICG visualization, the constant use of suction over the area of interest is the key maneuver to distinguish an artery rather than an extravascular fluorescein blood clot mimicking a vascular structure. In such situations, the possibility to have a simultaneous real-time visualization of fluorescent and non-fluorescent images on screen would have been very useful but is lacking in the current e-ICG technology available. General aspects and pros and cons of e-ICG use are summarized in Table 2.

Finally, the usefulness of e-ICG angiography in different fields of neurosurgery is increasingly acknowledged and there is still room for technical developments as more applications are developed and more experience is gained.

\section{Conclusions}

E-ICG presents as a safe and useful method, providing realtime and prolonged vascular information that can contribute to a significant improvement to clinical outcomes and consequently a reduction of major risks in several fields of neurosurgery. Future advancements of the e-ICG technology will 
improve the potential for the technique to become a critical tool for different applications in neurosurgery.

\section{Compliance with ethical standards}

Funding This study was not funded.

Conflict of interest The authors declare that they have no conflict of interest.

Ethical approval All procedures performed in studies involving human participants were in accordance with the ethical standards of the institutional and/or national research committee and with the 1964 Helsinki Declaration and its later amendments or comparable ethical standards.

Informed consent Informed consent was obtained from all individual participants included in the study.

Open Access This article is distributed under the terms of the Creative Commons Attribution 4.0 International License (http:// creativecommons.org/licenses/by/4.0/), which permits unrestricted use, distribution, and reproduction in any medium, provided you give appropriate credit to the original author(s) and the source, provide a link to the Creative Commons license, and indicate if changes were made.

\section{References}

1. Ben-Sira I, Riva CE (1975) Fluorescein diffusion in the human optic disc. Investig Ophthalmol 14:205-211

2. Betz CS, Zhorzel S, Schachenmayr H, Stepp H, Havel M, Siedek V, Leunig A, Matthias C, Hopper C, Harreus U (2009) Endoscopic measurements of free-flap perfusion in the head and neck region using red-excited indocyanine green: preliminary results. J Plast Reconstr Aesthet Surg 62:1602-1608. doi:10.1016/j.bjps.2008.07. 042

3. Bischoff PM, Flower RW (1985) Ten years experience with choroidal angiography using indocyanine green dye: a new routine examination or an epilogue? Documenta ophthalmologica Advances in ophthalmology 60:235-291

4. Holm C, Tegeler J, Mayr M, Becker A, Pfeiffer UJ, Muhlbauer W (2002) Monitoring free flaps using laser-induced fluorescence of indocyanine green: a preliminary experience. Microsurgery 22: 278-287. doi:10.1002/micr.10052

5. Patel KM, Bhanot P, Franklin B, Albino F, Nahabedian MY (2013) Use of intraoperative indocyanine-green angiography to minimize wound healing complications in abdominal wall reconstruction. J Plast Surg Hand Surg 47:476-480. doi:10.3109/2000656X.2013. 787085

6. Sekijima M, Tojimbara T, Sato S, Nakamura M, Kawase T, Kai K, Urashima Y, Nakajima I, Fuchinoue S, Teraoka S (2004) An intraoperative fluorescent imaging system in organ transplantation. Transplant Proc 36:2188-2190. doi:10.1016/j.transproceed.2004. 09.001

7. Sheidow TG, Blinder KJ, Holekamp N, Joseph D, Shah G, Grand MG, Thomas MA, Bakal J, Sharma S (2003) Outcome results in macular hole surgery: an evaluation of internal limiting membrane peeling with and without indocyanine green. Ophthalmology 110: 1697-1701. doi:10.1016/S0161-6420(03)00562-1

8. Soltesz EG, Laurence RG, De Grand AM, Cohn LH, Mihaljevic T, Frangioni JV (2007) Image-guided quantification of cardioplegia delivery during cardiac surgery. The heart surgery forum 10:E381E386. doi:10.1532/HSF98.20071099

9. Raabe A, Beck J, Gerlach R, Zimmermann M, Seifert V (2003) Near-infrared indocyanine green video angiography: a new method for intraoperative assessment of vascular flow. Neurosurgery 52 : 132-139 discussion 139

10. Raabe A, Beck J, Seifert V (2005) Technique and image quality of intraoperative indocyanine green angiography during aneurysm surgery using surgical microscope integrated near-infrared video technology. Zentralbl Neurochir 66:1-6; discussion 7-8. doi:10. 1055/s-2004-836223

11. Ferroli P, Acerbi F, Albanese E, Tringali G, Broggi M, Franzini A, Broggi G (2011) Application of intraoperative indocyanine green angiography for CNS tumors: results on the first 100 cases. Acta Neurochir Suppl 109:251-257. doi:10.1007/978-3-211-99651-5 40

12. Kim EH, Cho JM, Chang JH, Kim SH, Lee KS (2011) Application of intraoperative indocyanine green videoangiography to brain tumor surgery. Acta Neurochir 153:1487-1495; discussion 14941485. doi:10.1007/s00701-011-1046-x

13. Schubert GA, Barth M, Thome C (2010) The use of indocyanine green videography for intraoperative localization of intradural spinal tumors. Spine (Phila Pa 1976) 35:E212-E217. doi:10.1097/ BRS.0b013e3181bf25cc

14. Schubert GA, Schmieder K, Seiz-Rosenhagen M, Thome C (2011) ICG videography facilitates interpretation of vascular supply and anatomical landmarks in intramedullary spinal lesions: two case reports. Spine (Phila Pa 1976) 36:E811-E813. doi:10.1097/BRS. 0b013e3181fd6557

15. Takami T, Yamagata T, Naito K, Arima H, Ohata K (2013) Intraoperative assessment of spinal vascular flow in the surgery of spinal intramedullary tumors using indocyanine green videoangiography. Surg Neurol Int 4:135. doi:10.4103/21527806.119352

16. Bruneau M, Appelboom G, Rynkowski M, Van Cutsem N, Mine B, De Witte O (2013) Endoscope-integrated ICG technology: first application during intracranial aneurysm surgery. Neurosurg Rev 36:77-84; discussion 84-75. doi:10.1007/s10143-012-0419-9

17. Mielke D, Malinova V, Rohde V (2014) Comparison of intraoperative microscopic and endoscopic ICG angiography in aneurysm surgery. Neurosurgery 10(Suppl 3):418-425; discussion 425. doi: 10.1227/NEU.0000000000000345

18. Nishiyama Y, Kinouchi H, Senbokuya N, Kato T, Kanemaru K, Yoshioka H, Horikoshi T (2012) Endoscopic indocyanine green video angiography in aneurysm surgery: an innovative method for intraoperative assessment of blood flow in vasculature hidden from microscopic view. J Neurosurg 117:302-308. doi:10.3171/2012.5. JNS112300

19. Hide T, Yano S, Shinojima N, Kuratsu J (2015) Usefulness of the indocyanine green fluorescence endoscope in endonasal transsphenoidal surgery. J Neurosurg 122:1185-1192. doi:10. 3171/2014.9.JNS14599

20. Litvack ZN, Zada G, Laws ER Jr (2012) Indocyanine green fluorescence endoscopy for visual differentiation of pituitary tumor from surrounding structures. J Neurosurg 116:935-941. doi:10. 3171/2012.1.JNS11601

21. Simal Julian JA, Sanroman Alvarez P, Miranda Lloret P, Botella Asuncion C (2016) Endo ICG videoangiography: localizing the carotid artery in skull-base endonasal approaches. Acta Neurochir. doi:10.1007/s00701-016-2830-4

22. Tsuzuki S, Aihara Y, Eguchi S, Amano K, Kawamata T, Okada Y (2014) Application of indocyanine green (ICG) fluorescence for endoscopic biopsy of intraventricular tumors. Childs Nerv Syst 30:723-726. doi:10.1007/s00381-013-2266-6

23. Wachter D, Behm T, von Eckardstein K, Rohde V (2013) Indocyanine green angiography in endoscopic third 
ventriculostomy. Neurosurgery 73:ons67-ons72; ons72-6. doi:10. 1227/NEU.0b013e318285b846

24. Foersch S, Heimann A, Ayyad A, Spoden GA, Florin L, Mpoukouvalas K, Kiesslich R, Kempski O, Goetz M, Charalampaki P (2012) Confocal laser endomicroscopy for diagnosis and histomorphologic imaging of brain tumors in vivo. PLoS One 7:e41760. doi:10.1371/journal.pone.0041760

25. Inoue A, Ohnishi T, Kohno S, Nishida N, Nakamura Y, Ohtsuka Y, Matsumoto S, Ohue S (2015) Usefulness of an image fusion model using three-dimensional CT and MRI with indocyanine green fluorescence endoscopy as a multimodal assistant system in endoscopic transsphenoidal surgery. Int J Endocrinol 2015:694273. doi:10. $1155 / 2015 / 694273$

26. Yokoyama J, Ishibashi K, Shiramizu H, Ohba S (2016) Impact of endoscopic indocyanine green fluorescence imaging on superselective intra-arterial chemotherapy for recurrent cancer of the skull base. Anticancer Res 36:3419-3424

27. Yoshioka H, Kinouchi H (2015) The roles of endoscope in aneurysmal surgery. Neurol Med Chir (Tokyo) 55:469-478. doi:10. 2176/nmc.ra.2014-0428

28. Avery M, Chehab S, Wong JH, Mitha AP (2016) Intraoperative indocyanine green videoangiography to guide decision making regarding need for vessel bypass: a case report and technical note. Surg Neurol Int 7:S36-S39. doi:10.4103/2152-7806.173567
29. Jabbarli R, Pierscianek D, Wrede K, Dammann P, Schlamann M, Forsting M, Muller O, Sure U (2016) Aneurysm remnant after clipping: the risks and consequences. J Neurosurg 125:12491255. doi:10.3171/2015.10.JNS151536

30. Kubota H, Sanada Y, Nagatsuka K, Yoshioka H, Iwakura M, Kato A (2016) Safe and accurate sylvian dissection with the use of indocyanine green videoangiography. Surg Neurol Int 7:S427-S429. doi: $10.4103 / 2152-7806.183526$

31. Reinhart MB, Huntington CR, Blair LJ, Heniford BT, Augenstein VA (2016) Indocyanine green: historical context, current applications, and future considerations. Surg Innov 23:166-175. doi:10. $1177 / 1553350615604053$

32. Shah A, Rangarajan V, Kaswa A, Jain S, Goel A (2016) Indocyanine green as an adjunct for resection of insular gliomas. Asian journal of neurosurgery 11:276-281. doi:10.4103/17935482.175626

33. Alander JT, Kaartinen I, Laakso A, Patila T, Spillmann T, Tuchin VV, Venermo M, Valisuo P (2012) A review of indocyanine green fluorescent imaging in surgery. International journal of biomedical imaging 2012:940585. doi:10.1155/2012/940585

34. de Notaris M, Prats-Galino A, Ensenat J, Topczewski T, Ferrer E, Cavallo LM, Cappabianca P, Solari D (2014) Quantitative analysis of progressive removal of nasal structures during endoscopic suprasellar approach. Laryngoscope 124:2231-2237. doi:10.1002/ lary.24693 